\title{
CONSTRUCCIONES PREPOSICIONALES EN ORACIONES ESCINDIDAS: EL VALOR "EXISTENCIAL"
}

\author{
Emilio Cabezas Holgado \\ Universidad Complutense de Madrid
}

Recibido: 07/01/2015

Aceptado: 02/09/2015

\section{Resumen}

Las oraciones escindidas han sido descritas sobre la base de la relación predicativa 'especificativa' en el marco de las oraciones copulativas. Sin embargo, aquellas que se encuentran encabezadas por construcciones preposicionales presentan particularidades que afectan a las propiedades de concordancia, tanto de tiempo como de número, entre el elemento focalizado y la relativa libre, de modo que el valor que debe atribuirse al verbo ser en este tipo de secuencias es propiamente predicativo. Así, podrán distinguirse dos matices semánticos en relación con el sentido "existencial" de ser: el primero concierne a la noción de 'realidad concreta', mientras un segundo equivale a la de 'proceso de efectuación', constituyendo, a partir de este contraste, modos de acción 'atélicos' y 'télicos', respectivamente.

PALABRAS CLAVE: Preposición, predicación, sintaxis, escindida, foco

\begin{abstract}
Cleft Sentences have been described on the basis of the relationship 'predicative especificative' in the framework of the copulative sentences. However, those that are headed by prepositional constructions have characteristics which affect the properties of concordance, both time and number, between the cleaved element and the relative free construction, so that the value that must be attributed to the verb to be in this type of sequences is itself predicative. As well, may be distinguished two semantic nuances in relation to the direction "existential" to be: the first concerns the notion of 'reality', while a second is equivalent to the process of 'performance', forming, from this contrast, modes of action 'atelics' and 'telics', respectively.
\end{abstract}

\section{Introducción}

El estudio de las oraciones escindidas ha tratado de analizar el recurso de la focalización perifrástica como variante de construcciones copulativas con valor atributivo, o bien, de sentido identificativo especificativo ${ }^{1}$. Por lo tanto, ha quedado establecida una estructura

1 Fernández Leborans (2001) trata de distinguir adecuadamente la construcción escindida de la que no lo es, y de comprobar si, efectivamente, como se establece en la bibliografía, la estructura escindida puede inducir dos lecturas: la atributiva y la identificativa especificativa. En Fernández Leborans (1999) se señala que la interpretación atributiva de la oración copulativa con ser, el hablante asigna una propiedad o cualidad al sujeto, o lo adscribe a una clase (Juan es bueno; Mi hermano es biólogo); el orden de constituyentes es neutro, recto (el sujeto -que es la expresión referencial- aparece en posición inicial, y el predicado (el atributo, que es la expresión predicativa, descriptiva y, por tanto, no-referencial) ocupa la posición final. La interpretación identificativa puede ser de dos tipos: "descriptiva” (Juan es \{mi marido / el profesor de esgrima de mi hermano/ el padre de Julia) o "especificativa" ( $\{$ el culpable / el profesor de esgrima de mi hermano / el padre de Julia\} es Juan) 
sintáctica que "separa" un constituyente focal de naturaleza oracional o sintagmática a través de un verbo propiamente copulativo, permitiendo extraer una lectura bien diferenciada de aquella paráfrasis no circunlocutiva de la que deriva². Así:

(1) a. El que ha venido es Juan

b. Juan ha venido

(2) a. Es Juan el que me invitó

b. Juan me invitó

Obsérvese que las secuencias de (b) permiten inferir una relación de predicación canónica basada en: Referencia (Juan) + Descripción (ha venido/me invitó), mientras que sus derivadas (a) presentan una estructura de circunloquio (perifrástica) que conforma, a partir de una organización de la información relevante intencionadamente focalizada, un predicado de identificación especificativa; es decir, permiten que la Descripción (El que ha venido/el que me invitó) que conviene a la Referencia (Juan) restrinja un rasgo relativo al "reconocimiento de una entidad".

Resulta, por lo tanto, lógico que este tipo de oraciones haya recibido el tratamiento gramatical propio de las copulativas convencionales ${ }^{3}$. A saber, las particularidades sintácticas de concordancia flexiva y "armonía" categorial pueden probarse en cualquiera de las paráfrasis que corresponden a las secuencias de (1 a.) y (2 a.)

(3) a. Los que han venido son Juan y Luis

b. * Los que han venido es Juan

(4) a. Es él el vecino que llamó a la puerta

b. * Es hoy el vecino que llamó a la puerta

Tanto en ( 3 a.) como en (4 a.) puede cotejarse la flexión verbal con la naturaleza morfológica o sintáctica de número de los núcleos en relación de predicación: \{Los que + han venido + son + Juan y Luis $\} /\{$ Es + él + el vecino $+\ldots$ llamó... $\}$. Nótese la agramaticalidad de (3 b.) en este sentido. Por otro lado, es obligada, para alcanzar con éxito la conformidad semántica, la presencia de categorías nominales nucleares tanto en la expresión precopular como en la pospopular: $\{. . . e ́ l+$ el vecino... $\}$, de modo que la agramaticalidad de $(4 \mathrm{~b}$.) se desprende de la discordancia categorial que pretende identificar un núcleo nominal a partir de un adverbio temporal: $\{$...hoy + el vecino... $\}$

2 La Focalización es un procedimiento sintáctico o fonético que permite asignar la función de Foco de modo marcado a un determinado constituyente, por desplazamiento a posiciones anteriores o por asignación de prominencia fónica. Véase al respecto, Fernández Leborans (1991-92; 1999). En general, cuando se habla de construcciones escindidas se hace referencia al producto de una especie de proceso por el que se separa -se escinde- un constituyente de una oración y se sitúa antepuesto o pospuesto al verbo copulativo ser que se introduce en la construcción escindida. Dicho de otro modo, la 'escisión' sería un procedimiento sintáctico que permite derivar oraciones, denominadas escindidas, a partir de oraciones, digamos, indivisas (Fernández Leborans, 2001).

3 Para Plaza de la Ossa (2008) el verbo copulativo de las escindidas (VC) podría constituir un núcleo funcional de carácter presuposicional. "VC parece cumplir los requisitos que Abney enumeraba para caracterizar los núcleos funcionales: constituir clase léxica cerrada, ser fonológica y morfológicamente dependiente, permitir sólo un complemento en general que, además, no suele ser un argumento propiamente dicho sino un predicado, ser inseparable de su complemento y carecer de contenido descriptivo (más bien marcan rasgos gramaticales y/o relacionales)... En definitiva, esta situación aconseja orientar nuestra búsqueda hacia la suposición de que el VC contaría las mismas características de cualquier otro ser copulativo" 
Sin embargo, este análisis se hace extensivo a las oraciones escindidas encabezadas por construcciones preposicionales, a pesar de que estas presentan particularidades que contravienen, en primer lugar, la legitimidad de la relación de predicación basada en Referencia + Descripción (identificativa) y, en definitiva, no satisfacen las necesarias coincidencias sintácticas, en lo concerniente al rasgo flexivo de número (del que carecen los SSPP), y morfológicas, en relación con la categoría que se requiere para establecer una identificación especificativa entre núcleos de expresiones copulares ${ }^{4}$. Así:

(5) a. ?? A los que he llamado es a mis primos

b. ?? A mis primos es a los que he llamado

c. $*\{$ A los que he llamado/A mis primos $\}$ son $\{$ a mis primos/a los que he llamado

(6) a. ?? Con los que hablé es con Juan y Luis

b. ?? Con Juan y Luis es con los que hablé

c. ${ }^{*}\{$ Con los que hablé/Con Juan y Luis $\}$ son $\{$ con Juan y Luis/con los que hable $\}$

La dudosa gramaticalidad de (5 a./b.) y (6 a./b.) se debe a la concurrencia de diversos factores de naturaleza sintáctica, morfológica, semántica y pragmática, uno de los cuales, el que concierne a la concordancia, origina la agramaticalidad de (5 c.) y (6 c.), de modo que se hace necesario un análisis en mayor profundidad de los usos de ser en este tipo de oraciones.

Este trabajo tratará de presentar, desde una metodología descriptiva, datos que puedan arrojar luz acerca del estatus gramatical de las oraciones de "escisión" focalizadora que integran constituyentes de núcleo preposicional, de modo que sea posible determinar los valores semánticos que adquiere en estos casos el verbo ser, oscilantes entre los copulativos y los predicativos léxicos con sentido de "existencia", "acontecimiento", o bien, como se adoptará en este estudio, "proceder de un evento". Así, la organización de los contenidos se estructurará del siguiente modo:

El apartado 2 pondrá de manifiesto las diferencias fundamentales que afectan a la sintaxis y la semántica de las oraciones con ser copulativo y ser predicativo, haciendo especial hincapié en los usos de este último [2.1], descrito, frecuentemente, sobre la base de los contextos espacio-temporales. Por ello es por lo que estableceremos la división de dos clases fundamentales: la de aquellos que incluyen adjuntos y la que acoge construcciones "existenciales" que incorporan constituyentes predicativos [2.2]. Así, a lo largo del apartado 3 se describirá el comportamiento de las oraciones escindidas encabezadas por preposición, en oposición a aquellas que se construyen con núcleo nominal. Mostrando alternancias de flexión de tiempo podremos observar tendencias en relación con la concordancia en escindidas preposicionales y nominales [3.2], mientras que el contraste basado en la variación de la flexión de número resultará determinante para distinguir escindidas copulativas y escindidas predicativas [3.3].

Finalmente, en el apartado 4 analizaremos la gramaticalidad de las oraciones escindidas con preposición, atendiendo a la focalización del constituyente escindido y su valor sintáctico en el interior de la Relativa Libre $(\mathrm{RL})^{5}$.

4 En Fernández Leborans (2001) se concretan las particularidades de las denominadas oraciones escindidas (CopEs) y las pseudo-escindidas (RelEs) con constituyente escindido no preposicional

5 En Brucart (1999) se describen las relativas libres atendiendo a los contextos en los que puede aparecer este tipo de construcción, caracterizada por constituir el único representante fónico del SN en el que se insertan. 


\section{Valor predicativo de Ser}

2.1. El sentido de "existencia", "acontecimiento" o "sucesión de evento" en el verbo ser ha sido parcialmente descrito por los gramáticos a partir, fundamentalmente, de fórmulas introductorias convencionalizadas (Érase una vez...; Dios es; En el principio, era la palabra), de modo que se asocia a su valor predicativo la subcategorización de argumentos eventivos o complementos de localización espacio-temporal (El examen es esta tarde, La fiesta será en el piso de arriba, El registro de documentos es alli $)^{6}$.

Efectivamente, la distinción copulativo/predicativo radica en la especificación aspectual, relativa al 'modo de acción', que proporciona referencias de tipo 'estativo' a los usos copulativos y rasgos de 'dinamicidad' al valor predicativo, estableciendo una clara línea divisoria que separa dos entradas léxicas para ser. En este sentido, se ha argumentado que, en uso predicativo, ser, como verbo existencial o de acontecimiento, puede admitir expresiones locativas y/o temporales en calidad de complementos, no de predicados y es capaz de constituir predicado por sí mismo, sin que sea preciso interpretar complementos tácitos, supuestamente seleccionados: Eso no puede ser, Será lo que Dios quiera, Sea lo que sea ${ }^{7}$.

Sin embargo, es preciso determinar las clases estructurales que pueden presentar las oraciones de ser predicativo con complementación, diferenciando estas, a su vez, de las que no integran expresiones circunstanciales ${ }^{8}$.

Así, una primera división atiende a la incorporación de complementos de semántica diversa en un esquema $<$ ser $+(\mathrm{SD})+$ complemento/complemento $+(\mathrm{SD})+$ ser $>$, en oposición al que se muestra con la disposición $<\operatorname{ser}+(\mathrm{SD}) /(\mathrm{SD})+\operatorname{ser}>$.

Así, su distribución corresponde a la de los SSNN canónicos, de modo que cualquier núcleo léxico de SN puede ser conmutado por una relativa libre, siempre que el pronombre relativo que la encabece sea capaz de identificar los rasgos del antecedente vacío.

a. (La persona) Quien dice esto miente

b. (El lugar) Donde vive tu hermano es muy lejos

c. (El modo) Como lo dijo me pareció brusco

La Relativa Libre (RL) permite así focalizar la especificación de su antecedente tácito en una estructura de 'perifrástica' cuyos elementos constituyentes son: COP (CÓPULA) + CES (constituyente escindido) + RL (Relativa Libre). Véase Moreno Cabrera (1999).

6 La tradición gramatical vincula las expresiones locales con ser (es aquilno es muy lejos) al valor intransitivo originario de este verbo, que en la lengua medieval era frecuente Cfr: ¿dónde es la vaquera de la Finojosa? (recogido de Santillana, Serranillas, RAE 1973). Véase Bello 1847, Gili Gaya 1943 y RAE, 1973, 2009. La competencia con estar, relegó los usos de "existencia" de ser a las expresiones de convención bíblica.

7 En Fernández Leborans (1999) se señala que el verbo ser de acontecimiento o existencia es un verbo léxico, claramente distinto del verbo ser copulativo, que es, de hecho, la única cópula pura.

8 Entiéndase el término circunstancial desde un punto de vista semántico-interpretativo; es decir, relativo a la lectura que puede extraerse de secuencias del tipo: Eso es por tu bien (finalidad), Eso es sin querer (modal), Eso será si yo quiero (condicional), con independencia del estatus sintáctico que pueda asignarse a cada una de estas construcciones: ...por tu bien (adjunto),...sin querer (predicado),... si yo quiero (subordinación adjunta). 


\begin{tabular}{|l|l|}
\hline Ser + complementación & Ser $^{9}$ \\
\hline La reunión es \{esta tarde/a las diez/por la tarde/hoy\} & Eso (no) \{puede ser/es\} ${ }^{10}$ \\
El accidente fue \{en la calle Mayor/alli\} & Sea (lo que sea) \\
Aquello fue por culpa de Luis & Lo que es es \\
Esto es \{por una buena causa/para una buena causa\} & \\
Será si queremos todos & \\
Eso ha sido \{voluntariamente/así/sin mala intención/ & \\
con intención\} & \\
La discusión fue entre Juan y Luis & \\
\hline
\end{tabular}

Así, es posible conmutar por genuinos verbos de "existencia/acontecimiento", de forma natural, las secuencias de ser:

(7) a. Eso (no) \{puede \{suceder/existir/pasar\}/ \{sucede/existe/pasa\}\}

b. $\{$ Suceda/Exista/Pase $\}$ lo que $\{$ suceda/exista/pase $\}$

c. Lo que $\{$ sucede/existe/pasa\} \{sucede/existe/pasa\}

Sin embargo, puede observarse cierto matiz semántico en los datos de ser + complementación que aleja a estas construcciones de las anteriores, pues dicha estructura se asocia a la noción de 'efecto' u 'ocurrencia, mientras que la de ser se encuentra vinculada al sentido de 'realidad concreta de una entidad'. Por lo tanto, podría inferirse que la 'dinamicidad' propia del valor predicativo de ser se traduce en un modo de acción 'perecedero' en los usos con complementación, presentando así aspecto 'télico', mientras que la falta de complementos de naturaleza diversa (predicativa o adjunta) convierte a ser "existencial" en un verbo 'atélico'; es decir, una categoría que presenta aspecto léxico 'imperfectivo'. Adviértanse los contrastes de (8):

(8) a. $\{*$ Los dragones no $\{$ tienen lugar/ocurren/suceden $\}\}$ en nuestro mundo

b. Los dragones no \{existen/son reales\} (en nuestro mundo)

c. El accidente \{existió/fue real (* en la carretera de Extremadura)

d. $\{\#$ El accidente $\{$ tuvo lugar/ocurrió/sucedió\}\} en la carretera de Extremadura

La secuencia (8a.) resulta agramatical en ausencia de un complemento que sitúe espaciotemporal, modal, causal o condicionalmente la entidad que denota el SD los dragones, sin embargo, podría argumentarse que la agramaticalidad de la secuencia $<S D+$ verbo de acontecimiento $>$ radica en la naturaleza no eventiva de dicho SD. Nótese, no obstante, que la inclusión del complemento 'locativo' en nuestro mundo sí permite reinterpretar la semántica del sintagma los dragones como nombre de evento, similar a los casos siguientes:

9 Como señala Fernández Leborans (1999), no sería adecuado caracterizar el verbo ser de estas construcciones como verbo copulativo con predicados -atributos- tácitos.

10 No debe confundirse este uso con el propiamente copulativo de expresiones integradas en los contextos siguientes: Lo que me querías decir es que vendrías, ¿verdad? -Eso es -Ha dejado a su novia por mensaje y eso no es - Obsérvese que en estos casos sí podemos inferir un predicado atributivo implícito: -Es es (lo que te quería decir) -Eso no es (lógico/normal). 
(Las revueltas de) Los Claveles \{tienen lugar/ocurren/suceden\} en Portugal/ (Las batallas de) Los Trescientos \{tienen lugar/ocurren/suceden\} en las Termópilas/ (El desembarco de Normandia \{tiene lugar/ocurre/sucede\} entre la frontera de España y Holanda. Por otro lado, (8b.) puede integrar un complemento de la misma naturaleza conservando la gramaticalidad; no sin añadir un rasgo [+ dinámico] a la secuencia original que la acerca a la noción de 'proceso'. Cfr: Los dragones no \{existen/son reales\} en nuestro mundo, pero sí \{tienen lugar/ocurren\} en la mente de los niños ${ }^{11}$

Respecto a (8c.) la agramaticalidad se da con la aparición del complemento, debido a que este localiza la entidad de la que se predica la "acción de efectuarse" y se asocia a la propiedad léxica de un verbo de acontecimiento 'télico' como suceder u ocurrir. Así, con verbo de "existencia" la secuencia no requiere la presencia de complementos; caso contrario a (8d.), que resulta inapropiada en la interpretación de "acontecimiento perecedero" cuando no integra complemento, de modo que El accidente \{tuvo lugar/sucedió/ocurrió\} debe reinterpretarse como: El accidente \{existió/fue real\}

2.2. Por lo tanto, atendiendo a la naturaleza de los complementos que integran las construcciones de ser predicativo con sentido de "efecto" [2.1], podemos establecer una segunda división que distingue aquellas que expresan el "proceso" de un evento a partir de adjuntos 'circunstanciales' de las que lo hacen a través de un predicado de "posición/disposición". Así:

\begin{tabular}{|l|l|}
\hline Ser + complementación adjunta & Ser + complementación predicativa \\
\hline Esto es \{por una buena causa/para una buena & La reunión es \{en esta tardelen torno a las diez/ \\
causa\} & en Mayo\} \\
Será si queremos todos & La venta del artículo fue \{en mi casa/ante \\
Eso ha sido \{voluntariamentelasi\} & notario\} \\
& Eso ha sido \{con intención/sin intención\} \\
& La discusión fue entre Juan y Luis \\
\hline
\end{tabular}

El sentido de "proceso de efectuarse" al que hacemos referencia permite que la acción denotada por ser pueda enmarcarse en un campo espacial, temporal o coyuntural que determine el "desarrollo" del evento seleccionado por el verbo. Sin embargo, es preciso señalar que dicha determinación coyuntural puede interpretarse como el conjunto de "condicionamientos' que afectan directamente al "cumplimiento" de $\operatorname{ser}^{12}$, relativos a la temporalidad, la

11 Entiéndase como suceder u ocurrir en la mente como idea o concepto dragón. Como se recoge en DRAE (2014): Ocurrir:

6. prnl. Dicho de una idea: Venirse a la mente de repente y sin esperarla. Era u. $t$. c. intr.

En este último uso se asimila a ser predicativo.

En este sentido, ser se comporta como estar predicativo: Las tormentas están por todo el Norte. Véase Cabezas (2015).

12 Recuérdese que el sentido de ser léxico 'télico' es equivalente a efectuar

Efectuar.

prnl. Cumplirse, hacerse efectivo.

DRAE (2014) 
causa, la finalidad o la condición, de modo que las secuencias de $<$ Ser + complementación adjunta $>$ constituirían datos representativos de las siguientes circunstancias:

1.

La reunión es \{esta tarde/ a las diez/por la tarde/hoy\}:

Referencia temporal expresa a partir de SD (esta tarde), locución adverbial deíctica puntual (a las diez), locución adverbial deíctica amplia (por la tarde) y adverbio temporal pronominal (hoy)

\section{2.}

La venta del artículo fue \{desde casa/por Internet\}:

Referencia direccional expresa a partir de SP de 'origen' (desde casa) y SP de 'vía/ trayecto' $^{13}$ (por Internet)

\section{3.}

Aquello fue por culpa de Luis

Referencia causal expresa a partir de SP de 'vía/trayecto' (por culpa de Luis)

4.

Esto es \{por una buena causa/para una buena causa\}

Referencia final expresa a partir de SP de 'vía/trayecto' (por una buena causa) y SP de 'meta' (para una buena causa)

\section{5.}

Será si queremos todos

Referencia condicional expresa a partir de OSub.

\section{6.}

Eso ha sido \{voluntariamentelasi\}

Referencia modal expresa a partir de SAdv. (voluntariamente) y adverbio modal pronominal (asi)

Por otro lado, el valor léxico de ser "efectuación" puede completarse por medio de expresiones de 'estado resultante', 'situación' o 'ubicación'; es decir, predicados que indicarían el modo en que se presenta o resulta el evento (nombre eventivo) que integran las oraciones $<$ Ser + complementación predicativa $>$ :

\section{1.}

La reunión es \{en esta tardelen torno a las diez/en Mayo\}

Descripción espacial expresa a partir de SP 'locativo' de significación temporal inespecífica (en esta tarde), SP 'locativo’ de significación temporal específica (en torno a las diez) y SP 'locativo' ${ }^{14}$ de significación temporal amplia (en Mayo)

13 Sobre los valores léxicos de las preposiciones espaciales en español véase Cabezas (2015).

14 Consúltese la distinción 'locación'/'dirección' en relación con el estatus sintáctico de los SSPP espaciales en Cabezas $(2013,2015)$ 
2.

La venta del artículo fue \{en mi casa/ante notario\}

Descripción espacial expresa a partir de SP 'locativo' de significación de ubicación (en mi casa) y SP ‘locativo’ de significación de situación (ante notario)

3.

Eso ha sido \{con intención/sin intención\}

Descripción no espacial expresa a partir de SP de 'adición' (con intención) y SP de 'sustracción' ${ }^{15}$ (sin intención)

4.

La discusión fue entre Juan y Luis

Descripción espacial expresa a partir de SP 'locativo' de significación participativa ${ }^{16}$ (entre Juan y Luis)

Quedan, por lo tanto, establecidos los modelos estructurales que pueden asociarse al valor "existencial" télico de ser, de manera que sea posible analizar la sintaxis y la semántica de las oraciones escindidas encabezadas por construcciones preposicionales observando contrastes de gramaticalidad en función de las alternancias de flexión de tiempo y número.

\section{Escindidas copulativas y escindidas predicativas}

\subsection{Obsérvense los siguientes contrastes:}

(9) a. Juan es el que vino

b. Juan fue el que vino

c. Juan es el que vendrá

d. Juan será el que vendrá

(10) a. \# Con Juan es con quien vino

b. Con Juan fue con quien vino

c. \# Con Juan es con quien vendrá

d. Con Juan será con quien vendrá

Las secuencias de (9) muestran un comportamiento irrestricto respecto de la concordancia verbal entre el VC y el VR, pues se trata de construcciones escindidas en las que se especifica la referencia de un constituyente de naturaleza nominal; esto es, el elemento focalizado (ES) corresponde al antecedente nominal del pronombre integrado en la relativa (RL). El empleo de la concordancia pasada (pret. perf. = fue/vino) o futura (fut. imperf. =

15 Sobre el criterio de clasificación semántica de las preposiciones y, en particular, los valores léxicos de las preposiciones no espaciales véase Cabezas (2013, 2015)

16 En Cabezas $(2013,2014,2015)$ se describen los valores léxicos de la preposición entre sobre la base 'locativo-colectivo', de modo que todos los usos constituyen variantes de la propiedad de 'locación' en sentido recto o metaforizado. Así, la interpretación participativa se construye en la sintaxis como sigue: La discusión fue entre Juan y Luis = La discusión fue [(en [el espacio de confrontación]) [entre Juan y Luis]], donde el SP encabezado por en constituye el predicado del SD la discusión, integrando a su vez dicho SP una segunda relación de predicación a modo de CR (cláusula reducida): CR [el espacio de confrontación] [entre Juan y Luis] 
será/vendrá) en (9b.) y (9d.) supone la determinación del antecedente en el enclave de un tiempo específico, lo que no invalida el carácter de copulativa identificativa de la oración, ni la naturaleza aspectual 'atélica' de ser con este valor. Por otro lado, la ausencia de concordancia temporal en (9a.) y (9c.) señala, únicamente, un matiz estilístico en relación con el uso del tiempo presente, de modo que la expresión de 'intemporalidad' que este aporta puede traducirse como representativa de los denominados 'presentes gnómicos' ${ }^{17}$ o presentes del conocimiento, la universalidad o las verdades absolutas. Nótese que el contenido de cualquier construcción copulativa identificativa constituye una realidad o verdad 'estable"18.

(11) a. Juan es mi hermano/Mi hermano es Juan

b. Pedro Romero es el catedrático del departamento/El catedrático del departamento es Pedro Romero

c. Felipe de Habsburgo es Felipe I/Felipe I es Felipe de Habsburgo

d. Este es Luis/Luis es este

No obstante, los casos de concordancia en escindidas copulativas (con foco específico nominal) afectan, fundamentalmente, al aspecto verbal, pues es posible concertar el tiempo de la cópula (VC) y el tiempo de la relativa (VR) a través del matiz de 'continuidad' o 'resultatividad' que se extrae de la forma del verbo. Cfr: Juan fue el que había venido/* Juan era el que vino ${ }^{19}$. Por ello es por lo que se ha afirmado que el VC de este tipo de construcción

17 En Plaza de la Ossa (2008) se afirma: “...en este tipo de construcciones, el verbo copulativo es "intemporal'. De ahí que acepte con cualquier combinatoria la forma de presente de indicativo, la menos marcada temporalmente, puesto que el presente supone justamente la ausencia absoluta de precisión de tiempo, si bien, presenta un aspecto gramatical imperfectivo. Ese mismo presente de valor no temporal es utilizado en otros contextos: en aforismos, máximas, refranes, definiciones... Es lo que se conoce como "presente gnómico". Compárese:

a. Dos más dos suman cuatro

b. Tanto va el cántaro a la fuente, que al final se rompe

c. Es aquí donde tenía la tienda

c'. Era aquí donde tenía la tienda

c y c' serían semánticamente equivalentes, puesto que en ellas no se señala un lugar en el pasado. El acto de especificar el lugar se hace en tanto se está enunciando la frase. Cuando el VC va en imperfecto, mantiene ese valor de especificación ligada al enunciado y no a la existencia remota de la tienda en el pasado."

Moreno Cabrera (1999), por su parte, hace referencia al comportamiento irrestricto en relación con la concordancia de las escindidas copulativas haciendo hincapié en su carácter deíctico : "La PdR no describe [...] sino que señala este acto lingüístico de especificación y, por tanto, se trata de una construcción metalingüística: no señala nada sobre la realidad extralingüística, sino que es índice de una acción lingüística de que se deriva el peculiar comportamiento que acabamos de observar respecto de la concordancia temporal entre la cópula de las PdRs y el verbo principal de la oración expandida perifrástica"

18 En palabras de Fernández Leborans (1999), las oraciones copulativas con ser, en términos generales, contienen predicados 'estables' -predicados 'gnómicos' o predicados 'de individuos'.

19 La concordancia 'perfectivo'/'imperfectivo' se pone de manifiesto en secuencias análogas a las que se contrastan en Plaza de la Ossa (2008)

a. Fue aquí donde aparcaron a. *Fue aquí donde aparcaban

b. Era aquí donde aparcaron b. Era aquí donde aparcaban

c. Es aquí donde aparcaron c. Es aquí donde aparcaban

Como la autora señala: "mientras que si el VR es perfecto simple el VC puede aparecer en ese mismo tiempo, en presente de indicativo y en imperfecto de indicativo, si VR es imperfecto de indicativo sólo existe la opción de 
parece carecer de deixis temporal ${ }^{20}$, en contraposición a lo que se expresa en las secuencias de (10b.) y (10d.), en las que el verbo presenta rasgos léxicos propiamente temporales ${ }^{21}$ que pueden describirse del siguiente modo:

1.

Con Juan fue con quien vino

Lectura y paráfrasis: "El hecho de que (él/ella) viniera acompañado/a (junto a) \{de/ por\} alguien \{se produjo/se resolvió/se efectuó $\}$ acompañado/a (él/ella) (junto a) \{de/ por\} Juan"

Así \{se produjo/se resolvió/se efectuó\}\{Este/Ese/Aquel\} hecho

\section{2.}

Con Juan será con quien vendrá

Lectura y paráfrasis: "El hecho de que (é/ella) venga acompañado/a (junto a) \{de/ por\} alguien \{se producirá/se resolverá/se efectuará\} acompañado/a (él/ella) (junto a) $\{$ de/por\} Juan"

Así \{se producirá/se resolverá/se efectuará\} \{Este/Ese/Aquel\} hecho

Concluimos, a la luz de los datos, que las construcciones escindidas encabezadas por preposición constituyen usos de ser predicativo de aspecto 'télico' con la significación de "proceso de efectuación de un evento". Por otra parte, se trata de construcciones de $<$ ser + complementación adjunta $>$ que integran un complemento modal a la manera de

[6. Eso ha sido \{voluntariamente/asi\} Referencia modal expresa a partir de SAdv. (voluntariamente) y adverbio modal pronominal (asi)] [2.2]

Nótese que la relativa (RL) puede conmutarse por un logóforo pronominal y el elemento escindido (ES) se interpreta como adjunto ad-oracional de semántica modal: Eso \{fue/será\} así.

que VC sea presente o imperfecto de indicativo. Parece así que el VC concuerda temporalmente con el VR, pero no así en cuanto al aspecto. En este sentido, parece conservar el carácter imperfectivo de la forma de no tiempo del presente".

20 Tal afirmación se defiende en Plaza de la Ossa (2008): “... todo lo que podemos concluir es que este núcleo copulativo, al que por facilitar la identificación estamos llamando $\mathrm{VC}$, se trata en efecto de un núcleo donde los rasgos deícticos de tiempo parecen ausentes."

21 Las hipótesis de Bosque (1999) y Bošković (1997) que lo caracterizan como núcleo funcional parecen acordes con la observación que varios gramáticos tradicionales habían hecho acerca de la carencia de contenido semántico (de valor léxico, por tanto) de estas unidades. Navas Ruiz (1977) denomina a estos verbos "verbos de enlace o relación" y aclara:

Con objeto de poner de relieve o enfatizar un término de la oración, es frecuente en español sacarlo fuera de la misma y hacerlo depender de ser, que entonces no significa nada, reduciéndose a ser mero agente de enlace.

Recuérdese la polémica entre algunos gramáticos tradicionales como Navas Ruiz (1977) que agrupaban a los VC de las pseudocopulativas, por su nulo valor semántico, dentro de los usos predicativos o no copulativos del verbo "ser", y otros gramáticos actuales como Fernández Leborans (1999), quien considera que tal clasificación es una auténtica contradicción, dado que si los usos copulativos se distinguen por algo es por su carácter desemantizado frente a los usos predicativos donde se mantiene parte del significado léxico de su base latina ESS-RE. 
Por lo que respecta a las secuencias de (10a.) y (10c.), se han señalado como inapropiadas en la interpretación deseada por no presentar la concordancia temporal o aspectual que caracteriza a las anteriores ${ }^{22}$. De este modo, es lógico inferir que el valor "existencial" de $\operatorname{ser}$ en este uso deriva del sentido de 'realidad concreta de una entidad' ("existencia") propios de los que se estructuran por medio del esquema $<\operatorname{Ser}>$ (sin complementación) [2.1]. Es preciso, sin embargo, determinar en estos casos el estatus del elemento escindido (ES) con Juan en relación con ser predicativo. Pues bien, lo cierto es que en (10a.) y (10b.) el verbo ser expresa la "certeza de un hecho" que se interpreta con independencia del "proceso". Así"

\section{3.}

Con Juan es con quien vino

Lectura y paráfrasis: " $\{$ Es cierto/Es real $\}$ que con quien vino (él/ella) fue Juan” Eso es/Así es

\section{4.}

\section{Con Juan es con quien vendrá}

Lectura y paráfrasis: " $\{$ Es cierto/Es real $\}$ que con quien vendrá (él/ella) será Juan” Eso es/Así es

Véase que la estructura oracional disloca el constituyente que contiene el antecedente de la relativa $(\mathrm{RL})$ por cuestiones de focalización ${ }^{23}$, sin que este constituya complemento

22 Téngase en cuenta que las secuencias de (10b.) y (10d.) también admiten con naturalidad el concierto aspectual que señalábamos para las escindidas copulativas. Así:

a. Con Juan fue con quien había venido/* Con Juan era con quien vino

b. Con Juan será con quien venga/* Con Juan será con quien habrá venido

Como se indica, la solidaridad aspectual permite relacionar tiempos perfectos simples y compuestos en (a), así como futuros imperfectos y presentes de modo 'conjetural' o 'potencial' (b). Así, las variantes agramaticales resultan de la discordancia de aspecto en pasados de naturaleza 'atélica/télica' y en futuros cuya prospección encuentra continuidad o término respecto de la acción denotada por el verbo.

23 La dislocación en este sentido puede encontrase en construcciones 'de ascenso', en las que, por razones discursivas se sitúa en posición "prominente" un elemento extraído de un constituyente oracional subcategorizado: Vi a Juan salir de su casa = Vi que Juan salía de su casa.

Aunque no resultará determinante en nuestro estudio, dentro de las construcciones escindidas se han distinguido tres tipos atendiendo a su estructura:

- Oraciones escindidas: Es Pedro el que viene

- Oraciones pseudoescindidas: El que viene es Pedro

- Oraciones pseudoescindidas inversas: PEDRO es el que viene.

Como recuerda Fernández Leborans (2001), la terminología para referirse a cada una de las clases de escindidas varía según autores y escuelas: 'oraciones perifrásticas con ser' (Esbozo de la RAE), 'fórmulas perifrásticas de relativo’ (Fernández Ramírez), oraciones ecuacionales (Alarcos, entre otros). La bibliografía anglosajona usa el término 'cleft sentences' para referirse tanto a 'cleft o it-sentences' (escindidas o hendidas) como a 'pseudocleft o wh-sentences' (pseudoescindidas o pseudohendidas). Por su parte, Moreno Cabrera (1999) habla de PdR RL (pseudoescindida), PdR CES (pseudoescindida inversa) y PdR COP-CES (escindida).

En este sentido, Fernández Leborans (2003) señala que las oraciones escindidas son estructuras de "enfatización", pues el hablante atribuye al constituyente focal la relevancia contextual desde el punto de vista informativo, 
adjunto asociado a ser predicativo. Cfr: A París será a donde vaya = Así se resolverá la cuestión/A París es a donde vaya $=\#$ Así se resuelve la cuestión $=$ Así es $=($ Que a donde vaya sea a París) $e^{24}$.

\subsection{Téngase en consideración el siguiente contraste:}

(12) a. Juan es quien habla/*Juan y Luis es quien habla

b. Juan y Luis son quienes hablan/* Juan son quienes hablan

c. Todos son \{??quienes/los que\} hablan

(13) a. Con Juan es con quien hablo

b. * Con Juan y Luis son con quienes hablo/Con Juan y Luis es con \{quien/quienes\} hablo

c. ${ }^{*}$ Con todos son con $\{? ? q u i e n e s / l o s ~ q u e\}$ hablo/Con todos es con $\{?$ ?quienes/quien/los que/*el que\} hablo

Como puede inferirse, la concordancia en la flexión de número no solo se produce con absoluta naturalidad en las oraciones escindidas copulativas, sino que dicha relación de concordancia se presenta obligada, de modo que es clara la relación de predicación que se establece entre el núcleo nominal "focalizado" y la expresión descriptiva que constituye la construcción relativa. Cfr: [Juan] [quien habla]/ [Juan y Luis] [quienes hablan]. Nótese, no obstante, que en (12c.) el elemento nominal representado por pronombre indefinido (cuantificador universal ${ }^{25}$ ) difícilmente puede ser descrito a partir de un relativo de rasgo [+ animado [+ humano]] sin comportar dudosa gramaticalidad, por lo que resulta conveniente la asociación a un relativo [+ animado [inespecífico]]

Respecto a las secuencias de (13), hay que señalar que la concordancia de número entre el verbo ser predicativo (con sentido de "proceso de efectuación") y cualquiera de las expresiones - preverbales o posverbales- conlleva la agramaticalidad de toda la construcción. Sin embargo, es interesante indicar la lectura y paráfrasis correspondiente de estos usos.

de modo que, una oración escindida es, por definición, una estructura de "focalización". Así, aquellas que llevan el constituyente focal antepuesto son, de modo habitual, escindidas de Foco Contrastivo, sin que por ello comporten necesariamente información nueva.

24 En Fernández Leborans (2001) se define un tipo especial de construcción escindida: "Escindidas discontinuas; son oraciones íntegramente remáticas: tanto el «valor» como la «variable» contienen información 'nueva'. A diferencia de los otras dos subclases, en las que la función semántica de 'Especificación' no resulta subsidiaria respecto a la función pragmática de 'Focalización' o ‘Enfatización'...”, de modo que se presentan ejemplos de escindidas copulativas acompañadas de expresiones "existenciales” de naturaleza 'atélica': Quien redactó el proyecto fue José Antonio, ¿no es así?

25 Se comportan como todos los cuantificadores llamados "universales", cuya cardinalidad coincide con la totalidad del conjunto definido al que cuantifican. Frente a ellos, los "no universales" o "indefinidos" propiamente dichos denotan una parte indeterminada de un conjunto definido (en su interpretación partitiva) (a) o bien miden el tamaño de un conjunto indefinido de elementos (en su interpretación cardinal) (b). Véase Cabezas (2013) a partir de Sánchez López (1999).

a) Varios edificios fueron demolidos durante las obras

b) Algunos pensaban que deberían aplazarse las obras 
1. /2./3.

Con \{Juan/Juan y Luis/todos\} es con \{quien/quienes/los que\} hablo

Lectura y paráfrasis: "El hecho de que (yo) hable con \{alguien/algunas personas\} \{se produce/se resuelve/se efectúa\} hablando (yo) con $\{$ Juan/Juan y Luis/todos\}"

Asi \{se produce/se resuelve/se efectúa\} este hecho

Nótese que el vínculo entre elemento relativo y antecedente es problemático en (13c.), pues, a diferencia de (13b. $)^{26}$, presenta irregularidad gramatical. Cfr: Con Juan y Luis es con quien hablo/* Con todos es con el que hablo. El sorprendente contraste que se muestra en las secuencias anteriores se debe a la particularidad léxica de la preposición con, pues esta no selecciona (a diferencia de la preposición entre) un elemento nominal coordinado de naturaleza colectiva $^{27}$, sino que únicamente puede ser interpretada dicha coordinación como constituyente de carácter plural. Por ello es por lo que un sintagma como Juan y Luis, como argumento de preposición con, no expresa "conjunto", de modo que la lectura que corresponde a la construcción en la que se integra es la que sigue: "Con Juan y (con) Luis hablo/Es con Juan con el que hablo y también con Luis (con el que hablo)". Por el contrario, el cuantificador todos argumento de con sí puede atraer la concordancia plural del antecedente relativo: "Con todos hablo/Es con todos con los (seres humanos) que hablo", a pesar de que también permite ser interpretado como nombre 'colectivo': "Es con todos con quien (la entidad grupal que) hablo".

Concluimos, por lo tanto, que la concordancia de número resulta rasgo identificador determinante en la distinción entre oraciones escindidas copulativas y predicativas, atribuyendo a las primeras el concierto de número obligado y caracterizando las segundas a partir de la independencia flexiva del verbo regente (ser predicativo) respecto del verbo subordinado integrado en la relativa $(\mathrm{RL})^{28}$.

\section{El Foco preposicional en las escindidas}

El elemento focalizado en la construcción escindida (o pseudoescindida inversa) constituye la expresión remática (que contiene información nueva) en relación con la estructura argumental de la relativa, la cual proporciona información 'dada' (información' vieja') en el contexto precedente y determina un Tópico que es continuación de la línea temática

26 La secuencia de (13b.) Con Juan y Luis es con quienes hablo resulta gramatical aplicando la misma lectura que en Con Juan y Luis es con quien hablo: "Hablo con Juan y con Luis/Hablo con ambos/Hablo con dos personas", de modo que interpretamos más de un evento hablar - simultáneo o no-.

27 Véase Cabezas $(2013,2014)$ para la propiedad 'colectiva' asociada a la preposición entre, así como para profundizar en el valor de los sintagmas coordinados como argumentos de dicha preposición.

28 Plaza de la Ossa (2008) recuerda que Bosque (1999) y Fernández Leborans (2003) se refieren a la concordancia de número, señalando el primero la opcionalidad de la concordancia de número tanto en las escindidas como en las estructuras de focalización del español caribeño y precisando la segunda que solo en las pseudoescindidas inversas el Foco no atrae la concordancia de VC:

a. Lo que compraba eran legumbres

b. Eran legumbres lo que compraba

c. Legumbres era lo que compraba

Preferimos, en este estudio, trabajar con este último modelo de escindida por considerar que constituyen los casos de focalización más marcada, de modo que permite revelar el comportamiento sintáctico más dispar en relación con el contraste entre escindidas nominales y preposicionales. 
precedente ${ }^{29}$. Así, resulta obligado clasificar los SSPP "focalizadores" que encabezan las oraciones escindidas predicativas, así como determinar las relaciones sintácticas que se establecen entre estos y los elementos que integra la relativa libre (RL).

\begin{tabular}{|c|c|c|}
\hline Foco argumental & Foco adjunto & Foco predicativo \\
\hline $\begin{array}{l}\text { A Juan es a quien veo } \\
\text { De Gramática fue de lo que me } \\
\text { habló } \\
\text { Desde Madrid era desde donde } \\
\text { venía } \\
\text { Hacia Madrid es hacia donde } \\
\text { me dirijo } \\
\text { Hasta Mallorca fue hasta } \\
\text { donde llegó } \\
\text { Por la costa era por donde } \\
\text { cruzaban } \\
\text { Contra mi es contra quien se } \\
\text { enfrenta }\end{array}$ & $\begin{array}{l}\text { Desde mi casa es desde } \\
\text { donde me gusta comprar } \\
\text { antigüedades } \\
\text { Desde el año } 1990 \text { fue desde } \\
\text { cuando empezó a cantar } \\
\text { Hasta el año } 1990 \text { era hasta } \\
\text { cuando permanecía vigente su } \\
\text { contrato }\end{array}$ & $\begin{array}{l}\text { Ante mi es ante quien debe } \\
\text { postrarse } \\
\text { Con mi madre fue con quien } \\
\text { viajó a Mérida } \\
\text { En mi casa era donde se } \\
\text { encontraba } \\
\text { Sin ropa es como lo encontré } \\
\text { Sobre mis hombros fue como } \\
\text { entró en la ciudad } \\
\text { Tras mi séquito era donde } \\
\text { caminaba su hermano }\end{array}$ \\
\hline
\end{tabular}

Interesante contraste es el que puede observarse en el cuadro clasificatorio que presentamos arriba, pues las restricciones sintácticas que se infieren sobre la base de la presencia o ausencia de determinados SSPP como Focos de construcción escindida se desentrañan del siguiente modo:

\section{1. $\mathbf{F A}^{30}$}

Se trata, en su mayoría, de SSPP 'direccionales', de modo que establecen relaciones argumentales a partir de verbos de "desplazamiento" 31 que subcategorizan complementos regidos de 'origen': Desde Madrid era desde donde venía, 'meta': Hacia Madrid es hacia donde me dirijo (orientada) /Hasta Mallorca fue hasta donde llegó (alcanzada) o 'vía/trayectoria': Por la costa era por donde cruzaban. Nótese que las variantes de significación "temporal" en este tipo de construcción pasan a relacionarse como adjuntos verbales con el verbo de la relativa, constituyendo antecedentes de naturaleza adverbial. Sin embargo, tan solo los complementos 'direccionales' que señalan "punto específico" en relación con el segmento temporal expresado conservan el núcleo preposicional sintagmático. Cfr: Hacia las doce es cuando debe ocultarse/Por Navidad era cuando se atrevía a viajar.

Por otro lado, los objetos directos de persona y los complementos regidos canónicos pueden focalizarse a partir de SSPP encabezados por las preposiciones de 'restricción' ${ }^{32}: a$, o de 'dirección': de/contra con sentido figurado o "metaforizado" (de Gramática (hablar)/ contra mi (enfrentarse)).

\footnotetext{
29 Véase Fernández Leborans (2001).

30 Foco Argumental.

31 Véase Cabezas (2015).

32 En Cabezas (2014, 2015).
} 


\section{FAd ${ }^{33}$}

Como se ha señalado, únicamente SSPP de 'dirección' que señalen "puntos específicos” de referencia espacial o temporal pueden conservar su núcleo sintagmático tanto en posición de Foco como en el interior de la relativa: Desde casa...desde donde/Desde el año 1990... desde cuando/Hasta el año 1990...hasta cuando. Cfr: * Hacia las doce es hacia cuando....* Por Navidad era por cuando...

\section{3. $\mathbf{F P}^{34}$}

En todos los casos nos encontramos con SSPP 'locativos'/'situacionales' que presentan la particularidad de constituir antecedentes de relativos adverbiales. Dichos relativos describen 'estado' o 'disposición' de un argumento Objeto ${ }^{35}$ integrado en la relativa libre. Cfr: En mi casa...donde (estaba)/Sin ropa...como (estaba)/Sobre mis hombros...como (estaba)/ Tras mi séquito...donde (estaba). La excepción la representa la preposición con, pues como preposición 'aditiva' permite encabezar sintagmas que puedan interpretarse como "participantes complementarios" del argumento del que predican y con el que se asocian al evento denotado por el verbo: Con mi madre...con quien (viajaba) = Mi madre y él viajaban (juntos).

Respecto a la preposición entre, habría que señalar que su aparición en escindidas se limita a contextos "cooperativos" (de valor "sumativo'36), constituyendo así antecedente de un relativo adverbial modal: Entre todos fue como levantamos el piano. Nótese que su aparición en la relativa libre supone interpretar 'estado' orientado al sujeto (no al objeto directo el piano): Entre todos fue entre quienes levantamos el piano, con la lectura: "Nosotros levantamos el piano estando entre (en medio de) todos". Análogo comportamiento presentan los SSPP(con): Con Luis es con quien vi a María = "Vi a María estando (yo) con Luis".

Por último, es preciso hacer referencia al contraste sintáctico y semántico entre construcciones escindidas del tipo de (14) y (15).

(14) a. Allí es donde nos conocimos

b. Hoy es cuando vienen a recogerme

c. Así es como lo hago

(15) a. En Madrid fue donde nos conocimos

b. Sobre las dos es cuando vienen a recogerme

c. Sin herramientas era como lo hacía

Adviértase que las secuencias de (14) especifican un espacio local o temporal, o bien un modo a partir de la relación entre un elemento de naturaleza pronominal y un SD tácito: El lugar (donde)/El momento (cuando)/El modo (como). Por su parte, los datos de (15) se

33 Foco adjunto.

34 Foco predicativo.

35 El 'estado' de posición o situación se atribuye a un argumento que desempeña la función semántica (o papel temático) de Tema/Objeto, pues dicho argumento se comporta como agente en relación con un verbo como entrar o caminar, pero como objeto paciente en asociación con estar o encontrarse.

36 Cabezas (2015). 
encuentran encabezadas por expresiones de 'ubicación' espacial y temporal, así como por una construcción predicativa de 'situación': En Madrid/Sobre las dos/Sin herramientas, de modo que fuerzan la lectura de "proceso de efectuación" para ser, constituyendo oraciones escindidas de valor predicativo.

\section{Conclusiones}

Hemos descrito las oraciones escindidas encabezas por construcciones preposicionales atendiendo al valor "existencial" del verbo ser en este uso. Para ello establecemos una división que recoja los usos de "existencia" de las construcciones con ser, distinguiendo aquellas que presentan complementación de las que carecen de adjuntos 'circunstanciales'. De la inferencia que nos permite atribuir a las escindidas preposicionales un sentido de "proceso de efectuación”, podemos asociar aspecto ‘télico' al verbo regente, así como determinar contrates en relación con la concordancia de tiempo y número. Finalmente, hemos podido clasificar los Focos preposicionales de las escindidas predicativas atendiendo a su relación sintáctica con el argumento que integra la relativa libre.

\section{Referencias bibliográficas}

Bello, A. (1847): Gramática de la lengua castellana destinada al uso de los americanos, Edición crítica de R. Trujillo, Tenerife, Aula de Cultura de Tenerife, 1981.

Boscovic, Z.: "Pseudoclefts", Studia Linguistica, 51 (1997), pp. 235-277.

Bosque, I.: "On Focus vs. Wh- Movement: The Case of Caribbean Spanish", Sophia Linguistica Working Papers in Linguistics, 44/45 (1999), pp. 1-31.

Brucart, J. M.: "La estructura del sintagma nominal: las oraciones de relativo", en Ignacio Bosque y Violeta Demonte (eds.), Gramática descriptiva de la lengua española, Madrid, Espasa-Calpe, 1999, pp. 395-522.

Cabezas Holgado, E. (2013): La predicación: las construcciones “en abanico”: aplicaciones al español. Tesis Doctoral. Universidad Complutense de Madrid, http://eprints.ucm. es/22365/.

Cabezas Holgado, E. (2014). Sobre usos de la preposición entre: el sentido realizativo. Círculo de Lingüistica Aplicada a la Comunicación 58, 3-21.

Cabezas Holgado, E. (2014). 'Entre' la locación y la colección. Sobre las propiedades léxicas de una preposición bivalente DICENDA. Cuadernos de Filología Hispánica. 32, 7-31.

Cabezas Holgado, E. (2014) Construcciones encabezadas por la preposición entre. Valores y restricciones sintácticas" ELUA. Estudios de Lingüística de la Universidad de Alicante 28, 39-56.

Cabezas Holgado, E. La preposición I (2015) Colección Cuadernos de Lengua Española Madrid, Arco Libros.

Cabezas Holgado, E. La preposición II (2015) Colección Cuadernos de Lengua Española Madrid, Arco Libros.

Gili Gaya, S. (1943): Curso superior de sintaxis española, Barcelona, Biblograf, 1964.

Fernández Leborans, M. J.: "La predicación: las oraciones copulativas", en Ignacio Bosque y Violeta Demonte (eds.), Gramática descriptiva de la lengua española, Madrid, Espasa-Calpe, 1999, pp. 2357-2460. 
Fernández Leborans, M. J.: "Sobre formas de ambigüedad de las oraciones escindidas: sintaxis y discurso", Estudios de Lingüística de la Universidad de Alicante, 15 (2001), pp. 285-305.

Fernández Leborans, M. J.: "Sobre foco y concordancia en las perífrasis de relativo", en José Luis Girón Alconchel [et al.] (eds.), Estudios ofrecidos al profesor José Jesús de Bustos Tovar, Madrid, Universidad Complutense, 2003, pp. 99-113.

Moreno Cabrera, J.C. (1999): "Las funciones informativas: las perífrasis de relativo y otras construcciones perifrásticas", en I. Bosque y V. Demonte (comps.), Gramática Descriptiva de la Lengua Española. Madrid: Espasa-Calpe, vol. 3º cap. 65, 4245-4302.

Navas Ruiz, R.: Ser y estar, Salamanca, Ediciones Almar, 1977.

Plaza de la Ossa, M.: "Efectos de concordancia en las oraciones escindidas del español" DICENDA. Cuadernos de Filología Hispánica 2008, vol. 26 193-218.

Real Academia Española (1973): Esbozo de una nueva gramática de la lengua española, Madrid, Espasa-Calpe.

Real Academia Española (2001): Diccionario de la lengua española, 22 a edición, Madrid, Espasa-Calpe [DRAE-2001].

Real Academia Española (2009): Nueva Gramática de la Lengua Española, Madrid, Espasa Calpe.

Real Academia Española (2014): Diccionario de la lengua española, 23 a edición, Madrid, Espasa-Calpe [DRAE-2014].

Sánchez López, C. (1999): "Los cuantificadores: clases de cuantificadores y estructuras cuantificativas", en I. Bosque y V. Demonte (eds.): Gramática Descriptiva de la Lengua Española, vol. 1, 1025-1128. Madrid, Espasa Calpe. 